\title{
Electron Beam Melting and Refining of Niobium
}

\author{
Katsutoshi ONO and KIM YONG HWAN
}

Department of Metallurgy, Kyoto University, Yoshida-honmachi, Sakyo-ku, Kyoto, Kyoto-fu, 606 Japan.

(Received on November 8, 1991; accepted in final form on February 28, 1992)

\begin{abstract}
With respect to the importance of remelting of the ATR $-\mathrm{Nb}$ for the future large scale production of niobium applied to corrosion resistance materials and superconducting magnets with $\mathrm{Nb}-\mathrm{Ti}$ alloys, the electron beam melting and refining have been examined to the following items:

1) Process for the winning of niobium, 2) Thermochemical background for the melting and refining of niobium in vacuum, 3) Electron beam cold hearth remelting of niobium and 4) Purification of the ATR-Nb.

In this process, the electron beam furnace can act not only as remelting but also as refining apparatus. The experimental results showed its feasibility for obtaining niobium ingot of more than 99.8 mass\% purity from crude raw materials.
\end{abstract}

KEY WORDS: electron beam melting; niobium, refining; evaporation deoxidation.

\section{Introduction}

The potential applications of niobium to corrosion resistance materials is becoming recognized because of its unparalleled stability among various metals to a wide variety of corrosive environments. Moreover, a great quantity of niobium will be needed during 1992 and 1996 to fabricate superconducting magnets with $\mathrm{Nb}-\mathrm{Ti}$ wire for the Superconducting Super Collider. The raw material necessary to the large scale mass production for these applications in the future may surely be the aluminothermically reduced niobium (ATR-Nb).

In the last few decades, the electron beam techniques have been developed to a reliable, effective apparatus for melting of clean refractory metals and alloys. However, it must be noted especially in the case of the ATR-Nb that the electron beam furnace can play the role not only of melting but also of refining facility.

As a general rule, vacuum melting techniques are considered to be suitable for the elimination of gaseous impurities. The degree of purification resulting from the evaporation reactions is determined by the chemistry make-up of each particular system. For example, the electron beam melting is characterized by that the metal impurities can be evaporated under so high temperature as close to $3000 \mathrm{~K}$ and high vacuum and the oxygen which is present in the ATR-Nb in high concentration can be eliminated as evaporation deoxidation via volatile niobium suboxides, although such a purification is accompanied with considerable mass loss of base metal niobium.

The present work seeks to provide fundamental knowledge concerning the electron beam melting of the ATR- $\mathrm{Nb}$ from a thermochemical and kinetic point of view.

\section{Process for the Winning of Niobium}

One of the current states of art in producing pure niobium is indicated in Fig. 1. There is a variety of extraction and reduction processes corresponding to the purity and morphology of niobium to be extracted. The ultra-pure niobium is normally produced by the electrolysis of $\mathrm{K}_{2} \mathrm{NbF}_{7}$ or $\mathrm{NbCl}_{5}$ in molten salts, and the niobium powders are prepared by the sodium reduction of $\mathrm{K}_{2} \mathrm{NbF}_{7}$. The carbothermic reduction of $\mathrm{Nb}_{2} \mathrm{O}_{5}$ in vacuum has been made possible to fabricate the granular niobium. It is said that these processes are too expensive to be applied for mass production of niobium.

The aluminothermic reduction of $\mathrm{Nb}_{2} \mathrm{O}_{5}$ from

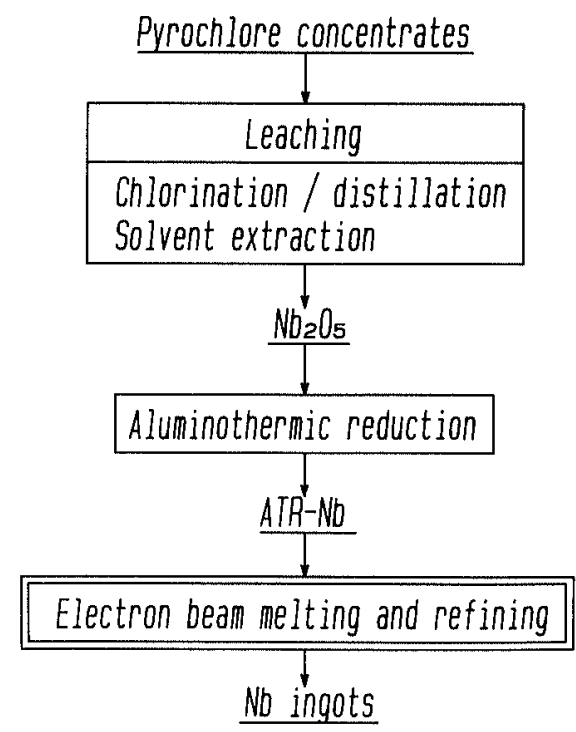

Fig. 1. Background of raw material to be melted and refined by electron beam bombardment in this study. 
Table 1. Chemical composition of the raw material and the niobium refined by the electron beam double melting.

\begin{tabular}{cccccccccccc}
\hline Materials & $\mathrm{Al}$ & $\mathrm{Si}$ & $\mathrm{W}$ & $\mathrm{Ta}$ & $\mathrm{Zr}$ & $\mathrm{Fe}$ & $\mathrm{Ni}$ & $\mathrm{Ti}$ & $\mathrm{C}$ & $\mathrm{O}$ & $\mathrm{N}$ \\
\hline $\begin{array}{c}\text { Raw material } \\
\text { (mass\%) }\end{array}$ & 1.8 & 0.15 & 0.05 & 0.19 & 0.008 & 0.12 & 0.005 & 0.008 & 0.05 & 2.8 & 0.08 \\
$\begin{array}{c}\text { 2nd melt } \mathrm{Nb} \\
\text { (mass\%) }\end{array}$ & 0.0038 & 0.0045 & 0.04 & 0.185 & 0.005 & 0.003 & 0.001 & 0.001 & 0.001 & 0.0087 & 0.0032 \\
\hline
\end{tabular}

pyrochlore processing followed by the electron beam melting may be applied on a much larger scale. In this process, the purity of niobium ingots does not depend directly on the purity of $\mathrm{Nb}_{2} \mathrm{O}_{5}$ to be reduced because the electron beam melting has an excellent function for niobium purification. Therefore, the electron beam melting and refining experiments in this study employed the ATR-Nb as starting material.

Typical chemical composition of the ATR-Nb is represented in Table 1, showing the very high residual oxygen and aluminum contents. The electron beam furnace has to refine this crude metal to the purity of at least 99.8 mass $\%$.

\section{Thermochemical Background for the Melting and Refining of Niobium}

\subsection{Basic Properties of Niobium in Relation to Vacuum Melting}

Beam power requirements for melting niobium are one of the most important factors but depend mainly on the furnace constitution, melting processes, drip melting and trough melting and residence time in molten state. However, it is essential in any case for evaluation of energy balance and thermal efficiency to use theoretical heat values calculated according to the equilibrium thermodynamic data.

The working conditions in the electron beam furnace, high temperature and high vacuum, lead inevitably to evaporation of base metal. In principle melting temperature is chosen so as not to exceed highly the melting point of the metal. Then, the vapor pressure over the melt of high-melting-point metal is much higher than that over the metal bath of lower melting point.

It is interesting to evaluate the rate of evaporation at the melting point. Change in molar volume of metallic vapor to temperature is given by,

$$
\frac{d V^{(\mathrm{g})}}{d T}=\frac{V^{(\mathrm{g})}}{T}\left(1-\frac{\Delta H}{R T}\right)
$$

where $V^{(g)}$ is molar volume of metallic vapor in equilibrium with the liquid metal, $\Delta H$ is the heat of evaporation and $R$ the gas constant. Equation (1) shows that in the condition, $\Delta H \gg R T, V^{(\mathrm{g})}$ decreases as temperature increases, or density of the vapor increases with temperature. If one assumes free surface evaporation, the maximum rate of evaporation in vacuum is expressed as,

$$
\frac{d N}{d t}=P^{\circ}\left(\frac{1}{2 \pi R T M}\right)^{1 / 2}
$$

where $N$ is the mole number of vaporizing metal, $P^{\circ}$ the
Table 2. Basic properties of $\mathrm{Nb}$ in relation to vacuum melting.

\begin{tabular}{lc}
\hline \multicolumn{1}{c}{ Parameters } & $\mathrm{Nb}$ \\
\hline Melting point $(\mathrm{K})$ & 2740 \\
Boiling point $(\mathrm{K})$ & 5008 \\
Heat of fusion $\left(H_{f}^{\circ} / \mathrm{kJ} \cdot \mathrm{mol}^{-1}\right)$ & 26.5 \\
Vapor pressure at melting point $(\mathrm{Pa})$ & 0.13 \\
Heat required to form molten state from & 99.6 \\
ambient temperature & \\
$\left(\left(H_{m . p}^{\circ}-H_{298 \mathrm{~K}}^{\circ}+\Delta H_{f}^{\circ}\right) / \mathrm{kJ} \cdot \mathrm{mol}^{-1}\right)$ & 685 \\
Heat of evaporation at melting point & \\
$\left(\Delta H_{e}^{\circ} / \mathrm{kJ} \cdot \mathrm{mol}^{-1}\right)$ & $6.6 \times 10^{20}$ \\
Evaporation rate at melting point & \\
$\left((d n / d t) / \mathrm{m}^{-2} \cdot \mathrm{s}^{-1}\right), n:$ number of atoms & \\
\hline
\end{tabular}

saturated vapor pressure of the metal and $M$ the atomic number. The theoretical rate of evaporation at melting point for niobium is represented in Table 2 calculated according to the Eq. (2) together with other thermochemical parameters computed using thermodynamic data collected by Barin and Knacke. ${ }^{1)}$

\subsection{Mass Spectrometric Investigation on the Evapora- tion Deoxidation of Niobium in Solid State}

Most of the refractory metals tend to form volatile oxides which have, in most cases, higher vapor pressure than their metals. Smith $e t$ al. ${ }^{2)}$ pointed out the potential importance of deoxidation of a metal via its suboxides. Brewer and Rosenblatt ${ }^{3)}$ discussed the possibility of purifying metals containing oxygen by vacuum melting. It has been said also for niobium purification that the volatile behavior of niobium suboxides, $\mathrm{NbO}$ and $\mathrm{NbO}_{2}$, plays an important role in the electron beam melting. However, so far direct examination of such gaseous species has not been made and the equilibrium partial pressure of the niobium suboxides over the niobium oxygen alloys has not been measured. Therefore, in this study mass spectrometric investigation has been conducted using the Knudsen-effusion method combined with a quadrupole mass filter. It is essential to carry out the measurements at the temperature above the melting point of niobium. But the equilibrium measurements have been done in solid state at temperatures as high as possible because of lack of crucible material to hold the liquid niobium for duration of equilibrium.

An assembly for the Knudsen cell-mass filter measurements is shown in Fig. 2. A quadrupole mass filter was connected to a high-temperature vacuum furnace with a cylindrical tantalum heater of $20 \mathrm{~mm}$ in diameter and $100 \mathrm{~mm}$ long. The temperature of the cell was measured by means of a W/Re 5-26 thermocouple. The molybdenum Knudsen cell was $12 \mathrm{~mm}$ in o.d., $9 \mathrm{~mm}$ 


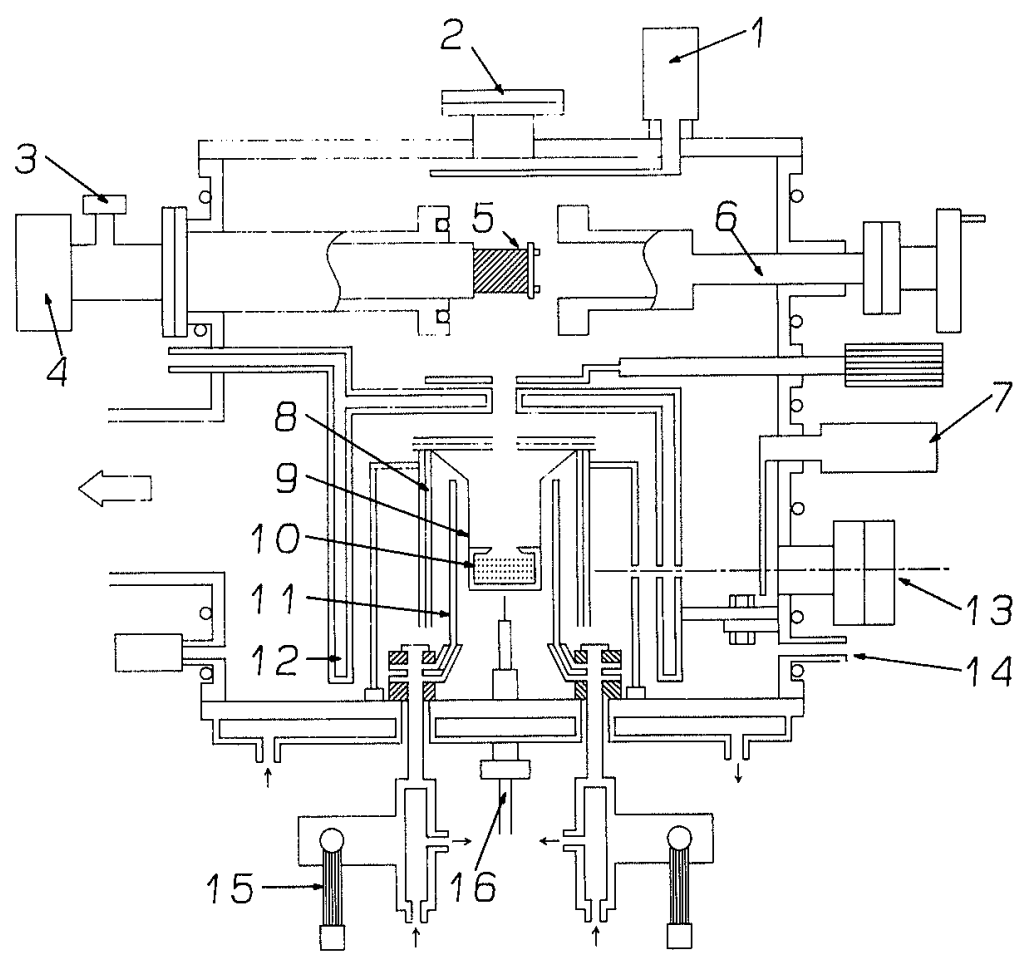

Fig. 2.

Assembly for Knudsen cell-mass filter measurements: 1. Shutter, 2. Viewing port, 3. Preamplifier, 4. HF unit, 5. Ion source, 6. Cut out valve, 7 . Shutter, 8. Ta radiation shield, 9. W wire, 10 Knudsen cell, 11. Ta heater, 12. Water jacket, 13. Sapphire window, 14. Leak port, 15. Power lead, 16. W-Re thermocouple.
Table 3. The gaseous ions in the $\mathrm{Nb}-\mathrm{O}$ binary system detected by the mass spectrometric measurements.

\begin{tabular}{lcc}
\hline Fields of the sample & $\begin{array}{c}\text { Temperature range } \\
(\mathrm{K})\end{array}$ & Detected ion species \\
\hline $\begin{array}{l}\mathrm{Nb}-\mathrm{O} \text { solid solution } \\
(4.8 \mathrm{~mol} \% \mathrm{O})\end{array}$ & $2123-2173$ & $\mathrm{Nb}^{+}, \mathrm{NbO}^{+}, \mathrm{NbO}_{2}^{+}$ \\
$\mathrm{Nb}-\mathrm{NbO}$ & $2023-2173$ & $\mathrm{Nb}^{+}, \mathrm{NbO}^{+}, \mathrm{NbO}_{2}^{+}$ \\
$\mathrm{NbO}-\mathrm{NbO}$ & $1973-2053$ & $\mathrm{Nb}^{+}, \mathrm{NbO}^{+}, \mathrm{NbO}_{2}^{+}$ \\
\hline
\end{tabular}

in i.d. and $7 \mathrm{~mm}$ in height, and the lid had a thickness of $2.4 \mathrm{~mm}$ and an orifice diameter of $0.2-0.5 \mathrm{~mm}$. The cell was suspended with tungsten wires in the tantalum heater.

The measured composition fields in the $\mathrm{Nb}-\mathrm{O}$ binary system were the $\mathrm{Nb}-\mathrm{O}$ solid solution, the $\mathrm{Nb}-\mathrm{NbO}$ and $\mathrm{NbO}-\mathrm{NbO}_{2}$ two-phase coexistence. The detected gaseous ions were summarized in Table 3. As seen in this table, the gaseous suboxide species were detected in each field of the $\mathrm{Nb}-\mathrm{O}$ system, confirming the suboxides evaporation during the electron beam melting of niobium containing oxygen.

It may be said from these facts that the residual niobium oxide $\mathrm{NbO}$ in the metal is decomposed to form volatile oxide $\mathrm{NbO}_{2}$ by the disproportionation reaction,

$$
2 \mathrm{NbO}=\mathrm{Nb}+\mathrm{NbO}_{2}(\mathrm{~g})
$$

and the oxygen dissolved in the metal combines with the base metal to form the gaseous oxide $\mathrm{NbO}$ and $\mathrm{NbO}_{2}$ according to the reactions,

$$
\begin{aligned}
& {[\mathrm{O}]_{\mathrm{Nb}}+\mathrm{Nb}=\mathrm{NbO}(\mathrm{g})} \\
& 2[\mathrm{O}]_{\mathrm{Nb}}+\mathrm{Nb}=\mathrm{NbO}_{2}(\mathrm{~g})
\end{aligned}
$$

Vapor pressure of the gas mixture of $\mathrm{NbO}$ and $\mathrm{NbO}_{2}$ over the $\mathrm{Nb}-\mathrm{NbO}$ two-phase coexistence were also measured by the Knudsen effusion method using the

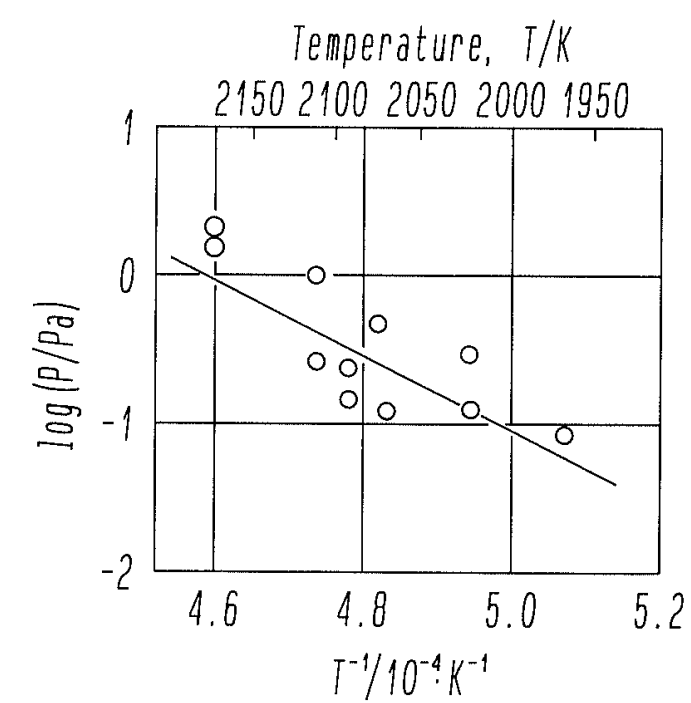

Fig. 3. Vapor pressure of $\mathrm{NbO}_{x}$ over the $\mathrm{Nb}-\mathrm{NbO}$ two-phase coexistence as function of temperature.

same set-up of the cell as Fig. 2. The results are shown in Fig. 3. The vapor pressure values are relatively high demonstrating a large evaporating tendency of the niobium suboxides.

\section{Electron Beam Cold Hearth Remelting of Niobium}

Industrial application of high power electron beam technology started with the melting of niobium and tantalum in high vacuum in a water-cooled copper crucible with a controlled processing rate consuming more energy than with any other vacuum melting process to get a ductile, cold forgeable metal. Continuous improvements in gun and power systems, process controls and furnace equipment have allowed the application of electron beam technology for larger scale melting and refining of refractory metals with the power 


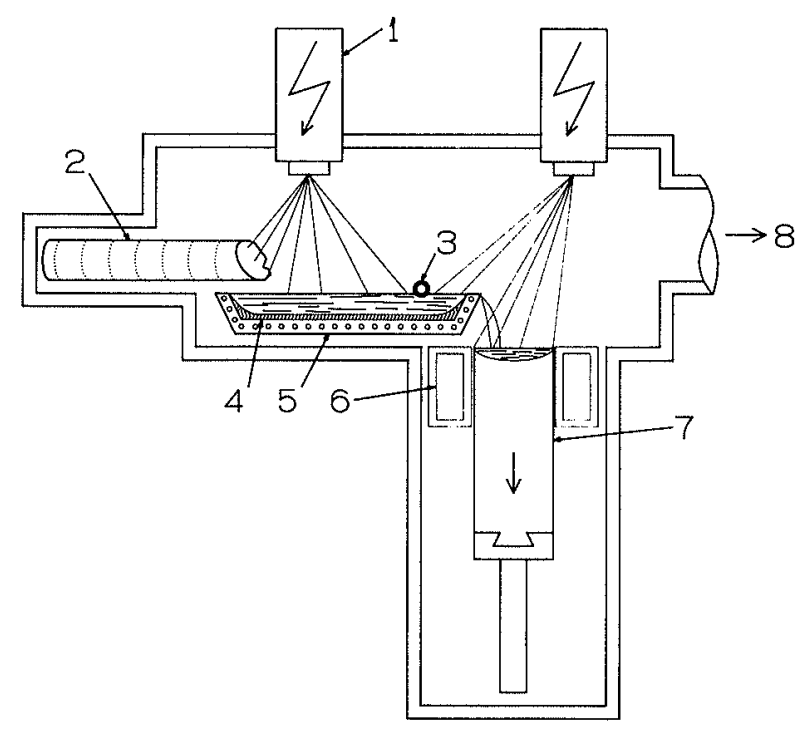

Fig. 4. Electron beam continuous flow melting of niobium: 1 . Electron beam gun, 2. Feedstock material, 3. Skimmer, 4. Freeze, 5. Trough, 6. Water-cooled copper crucible, 7. Niobium ingot, 8 . To vacuum pumping system.

\section{of $2000 \mathrm{~kW}$.}

The recent arrangement of guns, melt and crucible for the electron beam melting and refining of niobium is represented in Fig. 4. This study used the same system with a square cold hearth of 180 and $50 \mathrm{~mm}$ depth and a crystallizer to withdraw round ingot of $100 \mathrm{~mm} \mathrm{di}-$ ameter.

The beam bombards the face of the prepared stock of the ATR-Nb. The stock becomes liquidified and drops into the trough, where the low and high density inclusions are separated. Portion of the beam is applied to the pool enough to keep the metal in molten state. The degassing of impurities takes place for a part on the surface of the feed stock and for the most part on the molten pool surface. The overflow of the melt in the trough is poured into the ingot pool and solidified in a round or rectangular crucible which is used to withdraw directly a niobium slab. In general the molten pool is rather shallow although it depends on the electron beam power to be applied.

When the metal contains impurities in high concentration, bubbling and splashing take place during melting operation, owing to degassing from the interior of the melt. Nonmetallic inclusions are removed from the melt by flotation and coagulation and skimmed by the dam.

\section{Purification of the Alumino-reduced Niobium by the Electron Beam Melting}

A combination of low pressure, temperatures above the melting point of high-melting-point metals, and lack of contaminating materials in contact with the molten materials in the electron beam furnace provides the necessary condition for purification reactions. The process is then useful for the successful production of high purity niobium ingots from the crude ATR-Nb. Many examples of using an electron beam furnace in the vacuum melting of niobium have thus so far been reported, ${ }^{4-7)}$ and many authors have recognized the

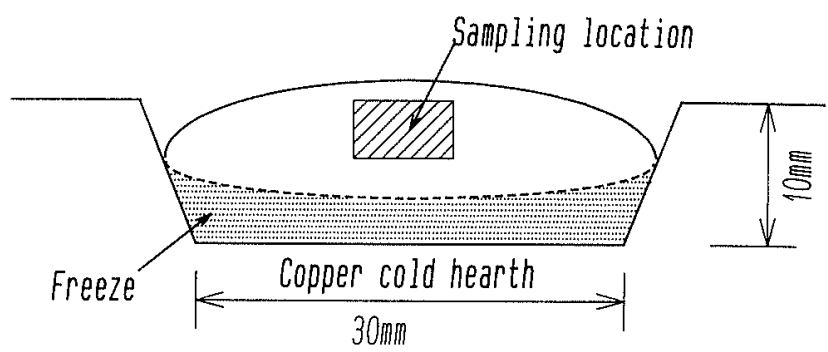

Fig. 5. Niobium button and sampling location.

great possibility for refining of niobium.

When impurity-bearing niobium being melted for the first time in an electron beam furnace violent outgassing and splattering often occur before a stationary molten pool is formed. It is supposed that the growth of gas bubbles in the molten metal due to the diffusive transfer of impurities originally dissolved in the metal plays an important role in the purification of the metals.

Change in composition of niobium occurring during electron beam melting depends on the residence time of the material in the molten state, the amount of superheat above the melting point, and the nature of the various species vaporizing from the melt. In this work the degree of purification resulting from these factors has been studied by measuring the change in impurity content as a function of melting time.

The electron beam furnace consisted of two guns rated at maximum $300 \mathrm{~kW}$ was used for vacuum degassing in a molten state. In each run, about $40 \mathrm{~g}$ of $\mathrm{Nb}$ powders with $99.9 \%$ purity were mixed with impurity metal powders and $\mathrm{Nb}_{2} \mathrm{O}_{5}$ powders as oxygen source into the initial impurity levels shown in Fig. 6, compacted in the form of pellet and melted under vacuum of $1.3 \times 10^{-2} \mathrm{~Pa}$.

Quenching of samples was achieved by interrupting the power supply; samples cooled from the experimental temperature to below red heat about $60 \mathrm{sec}$. For each run the electron beam of $0.3 \mathrm{~A}$ accelerated at $35 \mathrm{kV}$ was irradiated to the sample.

The niobium button is schematically shown in Fig. 5 together with the part of the button from which the sample for analysis was taken. The shape of the freeze zone was determined by dropping small tungsten markers into the melt and tracing the positions of their residence after solidified. The pool depth was rather shallow, about $5 \mathrm{~mm}$.

The results obtained are as follows. Aluminum and silicon contents were reduced to below 50 mass ppm from the initial content of 1 mass $\%$ within $120 \mathrm{sec}$. Iron level was decreased from 1 mass $\%$ to 100 mass ppm within $120 \mathrm{sec}$. On the other hand, oxygen was eliminated in much lower rate as seen in Fig. 6. Deoxidation was accelerated in the presence of $\mathrm{Al}, \mathrm{Si}$ and Mo. This may be due to the evaporation of these metals in the form of volatile oxides, $\mathrm{Al}_{2} \mathrm{O}, \mathrm{AlO}, \mathrm{SiO}$ and $\mathrm{MoO}_{3}$ especially during the initial period of melting when the oxygen concentration is relatively high. Final oxygen level in this degassing experiment was below 100 mass ppm.

The molten pool remains stable after the degassing from the interior of the molten metal has almost ceased and may be transferred to the surface evaporation. 


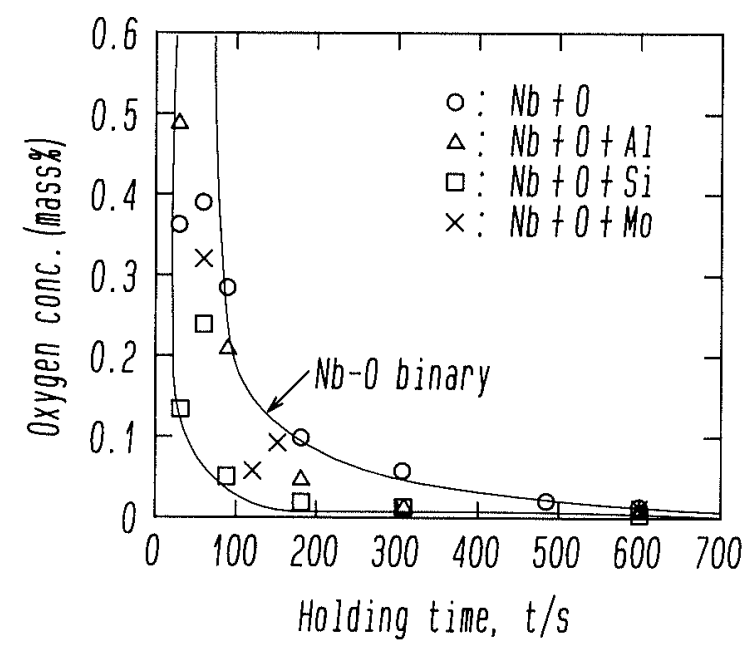

Fig. 6. Deoxidation of niobium. Initial contents (mass\%): $\mathrm{O}$ 2.5, Al 1.0, Si 1.0, Mo 1.0.

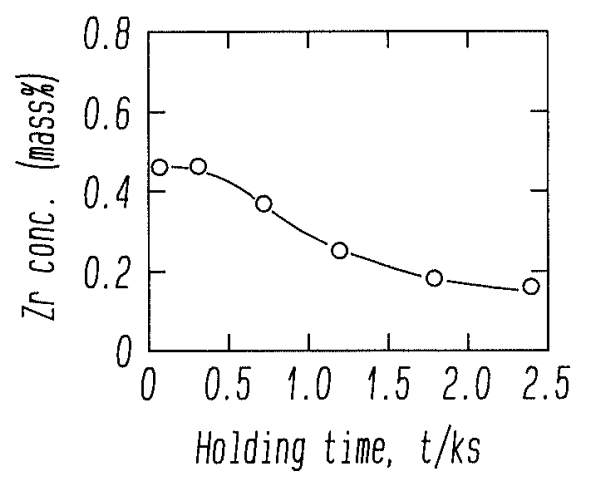

Fig. 7. Change in $\mathrm{Zr}$ concentration during the electron beam melting of niobium. Initial $\mathrm{Zr}$ content: $0.5 \mathrm{mass} \%$.

Mechanism of evaporation purification of $\mathrm{Nb}$ in liquid state has not so far been studied, but according to the previous work on the degassing from $\mathrm{Nb}$ in solid state at $2073-2473 \mathrm{~K},{ }^{8)}$ elementary steps of the degassing process may be described in the sequence as follow:

(1) Atoms dissolved in liquid metal body have to diffuse to the surface.

(2) Atoms diffused from the interior of the melt to its surface leave the dissolved state and pass into the state of adsorption at the surface, preferentially at the so-called active sites.

(3) The adsorbed atoms recombine to form molecules and leave the surface into vacuum. For the elimination of oxygen, the recombination of the atoms to form $\mathrm{NbO}$ or $\mathrm{NbO}_{2}$ molecules and the desorption of the molecules were thought to be rate-determining: Situation in the liquid state will be the same.

Nitrogen removal was much easier than oxygen, the level of 10 mass ppm being attained within $300 \mathrm{sec}$.

Besides above impurities, refractory metals such as tantalum and tungsten which are present in the ATR-Nb have no possibility to be eliminated by distillation. But slight diminution was observed for zirconium content as seen in Fig. 7. Molybdenum analysis in the deoxidized $\mathrm{Nb}$ revealed its deoxidation power only if excess oxygen is present before melting as seen in Fig. 8; Mo level decreased sharply at the initial melting stage, and

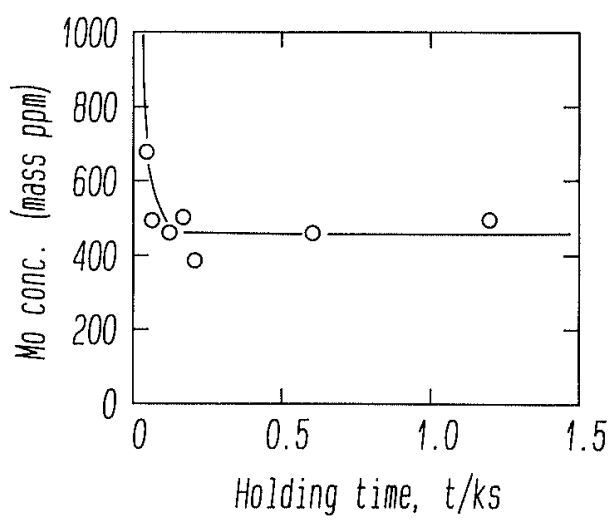

Fig. 8. Change in Mo content in $\mathrm{Nb}$ during the electron beam melting. Initial Mo concentration: 1.0 mass $\%$.

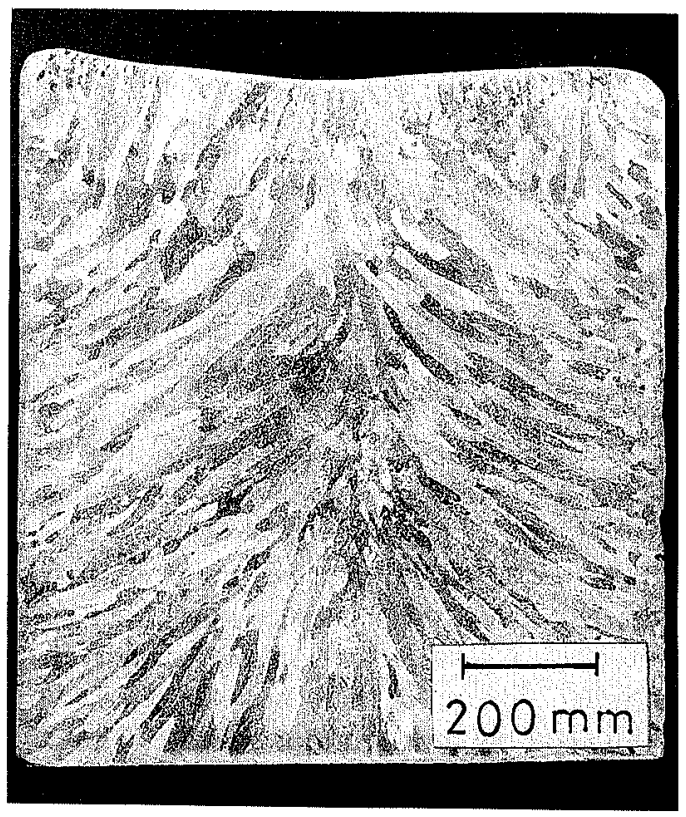

Fig. 9. Macrostructure of the niobium ingot produced by electron bean melting.

diminution of Mo content ceased after the oxygen concentration became small.

The ATR-Nb was melted into a round ingot of $100 \mathrm{~mm}$ dia. and $500 \mathrm{~mm}$ long using two guns rated at $52 \mathrm{~kW}$ and with the melting rate of $31.4 \mathrm{~kg} / \mathrm{h}$. Beam power efficiency which is the ratio of the heat required to form molten state at niobium melting point from ambient temperature to the total electric power consumption was calculated on the basis of the value listed in Table 1 to be $21.7 \%$ for this two guns trough melting.

The chemical compositions before and after double melting are represented in Table 3. Figure 9 shows the macrostructure of the ingot, exhibiting a columnar structure with uni-directional solidification.

\section{Conclusion}

The present study has focused on a few fundamental aspects concerning purification of the aluminothermic reduced niobium in an electron beam furnace. The experimental results showed the feasibility of the process except for elimination of refractory metals. 
ISIJ International, Vol. 32 (1992), No. 5

\section{REFERENCES}

1) I. Barin and O. Knacke: Thermochemical properties of inorganic substances, Springer-Verlag, Berlin, (1973).

2) H. R. Smith, C. Hunt and C. R. Hanks: J. Met., 11 (1959), 112.

3) L. Brewer and G. M. Rosenblatt: Trans. TMS-AIME, 224 (1962), 1268.

4) K. Schulze, O. Bach, D. Lupton and F. Schreiber: Niobium, Met.
Soc. AIME, Penn., (1983), 200.

5) K. Schulze: J. Met., (1981), May, 33.

6) C. K. Gupta, D. K. Bose and N. Krishnamurthy: J. Less-Common Met., 139 (1988), 189.

7) S. Uejo and K. Numa: J. Min. Mater. Proc. Inst. Jpn., 12 (1991), 865 .

8) K. Ono, Y. Ueda and J. Moriyama: J. Jpn. Inst. Met., 45 (1981), 463. 